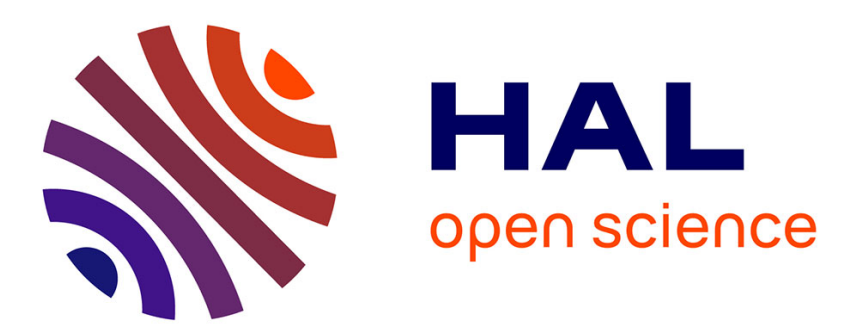

\title{
Experimental characterization of the different nitrogen dilution effects on soot formation in ethylene diffusion flames
}

\author{
Qianlong Wang, Guillaume Legros, Jérôme Bonnety, Céline Morin
}

\section{- To cite this version:}

Qianlong Wang, Guillaume Legros, Jérôme Bonnety, Céline Morin. Experimental characterization of the different nitrogen dilution effects on soot formation in ethylene diffusion flames. Proceedings of the Combustion Institute, 2017, 36 (2), pp.3227-3235. 10.1016/j.proci.2016.07.063 . hal-01433558

\section{HAL Id: hal-01433558 \\ https://hal.sorbonne-universite.fr/hal-01433558}

Submitted on 12 Jan 2017

HAL is a multi-disciplinary open access archive for the deposit and dissemination of scientific research documents, whether they are published or not. The documents may come from teaching and research institutions in France or abroad, or from public or private research centers.
L'archive ouverte pluridisciplinaire HAL, est destinée au dépôt et à la diffusion de documents scientifiques de niveau recherche, publiés ou non, émanant des établissements d'enseignement et de recherche français ou étrangers, des laboratoires publics ou privés. 


\title{
Experimental characterization of the different nitrogen dilution effects on soot formation in ethylene diffusion flames
}

\author{
Q. Wang*,a, G. Legros ${ }^{\mathrm{b}}$, J. Bonnety ${ }^{\mathrm{b}}$, C. Morin ${ }^{\mathrm{c}}$ \\ ${ }^{a}$ Shanghai JiaoTong University, School of Mechanical Engineering, Shanghai, China \\ ${ }^{b}$ Sorbonne Universités, UPMC Univ Paris 06, CNRS, UMR 7190 Institut Jean le Rond \\ d'Alembert, F-75005 Paris, France \\ ${ }^{c}$ LAMIH CNRS UMR 8201, UVHC, F-59313 Valenciennes, France
}

\begin{abstract}
This paper addresses the discrimination of dilution and thermal effects on soot production when nitrogen is added to the fuel stream of a steady laminar ethylene diffusion flame. In this context, the mixture-strength flame height $H_{f}$ and visible flame height $H_{v}$ are unambiguously documented and exhibit opposite trends within experimental diluted range $\left(N_{2}\right.$ volume fraction from 0 to 0.56). Simultaneous soot volume fraction and temperature fields are mapped for different $N_{2}$ volume fractions by the Modulated Absorption/Emission (MAE) technique. Two characteristic flame heights and the temperature at the peak soot volume fraction are shown to be crucial parameters to assess the extent of the dilution and thermal effects together with their impact on soot formation in the flame. As a result, the mixture-strength flame height is proposed to characterize the soot formation rate within soot growth region, while the visible flame height is more appropriate to describe the overall sooting propensity in the flame. The probed soot temperature is recommended as the characteristic temperature to assess $N_{2}$ dilution and thermal effects since the thermal effect is overestimated when using the adiabatic temperature.
\end{abstract}

Keywords: Soot, diffusion flame, dilution effect, thermal effect

Acronyms: FGR Flue Gas Recirculation; EGR Exhaust Gas Recirculation; 
LFL Low Flammability Limit; CFD Computational Fluid Dynamics; MAE Modulated Absorption Emission; LHS Left Hand Side; SVF Soot Volume Fraction; HAB Height Above Burner 


\section{Introduction}

Within the context of growing concerns on the environmental issues, public health, and high-efficiency energy utilization, strategies aiming at the mitigation of soot production by combustion devices have attracted considerable attention. The Flue Gas Recirculation (FGR) and Exhaust Gas Recirculation (EGR) are reported as technologies potentially suppressing soot release by reducing the overall combustion temperature and ignition delay within high levels of EGR dilution in Diesel engine [1]. As a result, fundamental investigations to assess FGR/EGR strategies consist in adding specific gaseous species to the fuel and/or the oxidizer of the reacting flows. As an illustration, species such as $N_{2}$ or $\mathrm{H}_{2} \mathrm{O}$ added to a fuel mixture lead to a significant modification of the Lower Flammability Limit (LFL). Therefore, further insights into the correlation between soot production and temperature field in diluted flames are also crucial to practical concerns like fire safety.

As discussed by Du et al. [2] and Liu et al. [3], the reduction of soot formation resulting from the introduction of inert gaseous additives, such as $N_{2}$ or Ar, can be attributed to two main effects, i.e. a dilution effect because of the reduction in the concentrations of the reactive species; and a thermal effect due to the change in flame temperature as a consequence of the streams' physical properties variation.

When a reactive species such as $\mathrm{CO}_{2}$ or $\mathrm{H}_{2} \mathrm{O}$ is added, the chemical effect also reveals. Although completely isolating the chemical effect from the other two is impossible, several experimental studies were conducted to assess the extent of the chemical effect [4]. While CFD can resolve all effects, it still requires experimental trends for careful validation. Experimental trends exhibited by the chemical effect may contribute to this effort [3].

Several studies delivered significant insights into the discrimination of the 
dilution and thermal effects. Axelbaum and Law [5] suggested a modelling formulation of the soot formation rate when affected by an inert dilution, i.e. $X_{F}^{a} * \exp \left(-E_{a} / R^{0} T\right)$. Here $X_{F}$ is the initial fuel volume fraction in the fuel stream and $a$ is the order of dependence of soot formation rate on fuel volume fraction. $\quad R^{0}$ is the ideal gas constant and $E_{a}$ is the activation energy. In this equation, $X_{F}^{a}$ and the Arrhenius law represent the dilution and thermal effects, respectively. The relative importance of both effects were quantified and an activation energy $E_{a}$ of $209 \mathrm{~kJ} / \mathrm{mol}$ was extracted by Axelbaum and Law from the measurements of soot volume fraction in a laminar diffusion flame established over a coflow burner where the $N_{2}$ dilution of the ethylene stream could be adjusted. Later on, Gülder et al. [6] incorporated the flame height and diameter into the model of soot formation rate to account for the influence of flame geometry variation on the sooting tendency. These authors evaluated a smaller activation energy of $200 \mathrm{~kJ} / \mathrm{mol}$. Two potential flame heights were identified. The visible flame height, referred to as $H_{v}$ in the following, can be imaged and measured experimentally [7]. Alternatively, the mixture-strength height, referred to as $H_{f}$, is defined as the distance from the burner tip to the upper location where the local equivalence ratio along the centerline is equal to unity [8]. Thus, the selection of the characteristic flame height affects the evaluation of the magnitude of the dilution and thermal effects acting on the soot formation $[2,9,10]$.

Interestingly, both groups of authors selected the theoretical adiabatic temperature as the characteristic temperature in the Arrhenius law to take into account the effects of the inert addition on the flame temperature. Nevertheless, radiative heat losses attributed to soot particles leads to lower actual peak temperature [11]. For this reason, Du et al. [9] used the maximum flame temperature measured by a thermocouple probing the flame. These authors obtained 
a global activation energy of $130 \mathrm{~kJ} / \mathrm{mol}$. However, the use of a thermocouple is an intrusive technique that exhibits a quite low spatial resolution and a relatively high uncertainty range, especially when soot deposit can alter the sensitivity of the thermocouple [10]. Consequently, the present study focuses on the discrimination of the dilution and thermal effects on soot production due to $N_{2}$ dilution of the fuel stream in atmospheric steady laminar diffusion flames. This further examination is motivated by the recent extension of the modulated absorption/emission (MAE) technique to two-dimensional flames by Legros et al. [12], by which both fields of soot temperature and volume fraction can be measured simultaneously. Following the aforementioned studies $[5,6]$, the evaluation of the dilution and thermal effects can be refined.

\section{Experimental methodology}

\subsection{Burner}

The diffusion flames are established over an axisymmetric coflow burner identical to the one described by Santoro et al. [13] and used in previous investigations $[14,15,16]$.

The fuel stream consists of ethylene $\left(\mathrm{C}_{2} \mathrm{H}_{4}\right)$ that can be nitrogen diluted. Ethylene and nitrogen come from high-purity gas cylinders (99.9\% stated purities). Two Bronkhorst EL-FLOW mass flow controllers enable the variations of both the ethylene and nitrogen flow rates. The fuel stream flows through a vertical axial brass duct of $11 \mathrm{~mm}$ inner diameter. This axial duct is straight

over a distance of $250 \mathrm{~mm}$ upstream its tip so the exit velocity profile can be assumed fully-developed over the range of investigated ethylene flow rates.

The coflowing stream consists of filtered compressed air. Another mass flow controller allows the air flow rate to be adjusted. Air is then introduced into a concentric $102 \mathrm{~mm}$ inner diameter brass cylinder. A perforated brass plate, 
glass beads, and finally a ceramic honeycomb straighten the oxidizer flow. The fuel tube extends $3 \mathrm{~mm}$ above the honeycomb surface.

For the present study, the flow rates of the ethylene stream and coflowing air are adjusted at the constant values of $0.231 \mathrm{l} / \mathrm{min}$ and $43 \mathrm{l} / \mathrm{min}$, respectively. Nitrogen is added to the ethylene stream at a flow rate ranging from 0 to $0.3 \mathrm{l} / \mathrm{min}$. The adiabatic temperatures are then calculated for every dilution condition investigated, as reported in Tab.1. Beyond $X_{N_{2}}=56 \%$, the low level of soot formed in the flame cannot be detected by the MAE technique. As a result, the $X_{N_{2}}$ range is constrained to $0-56 \%$.

Table 1: Experimental parameters and constants.

\begin{tabular}{|c|c|c|c|c|c|}
\hline \multicolumn{3}{|c|}{ fuel flow } & coflow & \multicolumn{2}{|c|}{ temperature } \\
\hline $\begin{array}{l}\mathrm{C}_{2} \mathrm{H}_{4} \\
(\mathrm{l} / \mathrm{min})\end{array}$ & $\begin{array}{c}N_{2} \\
(\mathrm{l} / \mathrm{min})\end{array}$ & $X_{N_{2}}$ & $\begin{array}{c}\text { Air } \\
(\mathrm{l} / \mathrm{min})\end{array}$ & $\begin{array}{c}\text { adiabatic temperature } \\
(\mathrm{K})\end{array}$ & $\begin{array}{c}\text { max. soot temperature } \\
\text { measured }( \pm 50 \mathrm{~K})\end{array}$ \\
\hline \multirow{8}{*}{0.231} & 0 & 0 & \multirow{8}{*}{43} & 2363 & 1712 \\
\hline & 0.02 & $8 \%$ & & 2348 & 1686 \\
\hline & 0.06 & $20 \%$ & & 2331 & 1668 \\
\hline & 0.09 & $28 \%$ & & 2309 & 1663 \\
\hline & 0.11 & $32 \%$ & & 2300 & 1682 \\
\hline & 0.14 & $38 \%$ & & 2292 & 1685 \\
\hline & 0.2 & $46 \%$ & & 2271 & 1605 \\
\hline & 0.3 & $56 \%$ & & 2235 & 1594 \\
\hline
\end{tabular}

\subsection{Scaling soot formation}

To discriminate the relative importance of the dilution and thermal effects, Gülder et al. [6] assumed that soot formation rate $\dot{m}_{\text {soot }}^{\prime}$ in diffusion flames is governed by Eq.(1):

$$
\dot{m}_{\text {soot }}^{\prime} \propto\left[X_{F}\right]^{a} \frac{\sqrt{H}}{L_{\max }} \exp \left(\frac{-E_{a}}{R^{0} T}\right)
$$

The influence of inert dilution on $\dot{m}_{\text {soot }}^{\prime}$ then mainly arises from a direct 
reduction in $X_{F}$ associated with the lower diluted fuel concentration and an indirect thermal reduction in flame temperature T. $a$ is assumed to be unity since nitrogen has comparable diffusion coefficient to that of the fuel and the oxidizer [17]. Here $H$ is flame height and $L_{\max }$ is the flame diameter at the axial location of the peak soot volume fraction. In Eq.(1), the influence of the flame geometry variation due to dilution is introduced by the ratio $\sqrt{H} / L_{\max }$. Indeed, the soot residence time in a laminar diffusion flame is proportional to $\sqrt{H}[6]$. Though the soot formation rate normally varies with the location in the flame, the soot formation along the flame's axis is here assumed independent from the soot oxidation, except in the flame tip region.

Thus, the characteristic soot formation rate $\dot{m}_{\text {soot }}^{\prime}$ can be related to the mean first derivative of the average soot volume fraction $F_{\text {soot }}$ along the flame axis:

$$
\dot{m}_{\text {soot }}^{\prime}=\Delta F_{\text {soot }}(z) / \Delta t \propto \frac{X_{F} \sqrt{H}}{L_{\max }} \exp \left(\frac{-E_{a}}{R^{0} T}\right)
$$

$F_{\text {soot }}(z)$ is the average soot volume fraction within the entire section of the flame at a given $z$ along the axis, defined as follows:

$$
F_{\text {soot }}(z)=\frac{\lambda / L(z)}{6 \pi E(m)} \ln \left(\tau_{\lambda}(z)\right)
$$

Here $z$ is the height above the burner (HAB), $L(z)$ is the flame diameter along the height, $\lambda$ is the wavelength at which the transmissivity $\tau$ along the line-of-sight crossing the flame is evaluated, and $\mathrm{E}(\mathrm{m})$ is the soot refractive index. As a result, Eq.(1) can be written as follows [6]: 


$$
F_{\max } \propto \frac{X_{F} \sqrt{H}}{L_{\max }} \exp \left(\frac{-E_{a}}{R^{0} T}\right)
$$

In Eq.(4), $F_{\max }$, where $\Delta F_{\text {soot }}(z) / \Delta t$ equals zero, is considered as the characteristic soot formation rate. All the parameters can be determined experimentally to allow for an empirical evaluation of the activation energy $E_{a}$. Doing so, the selection of the flame height $H$ and the characteristic flame temperature $T$ plays a crucial role in the evaluation of the dilution and thermal effects. As mentioned earlier, two flame heights could be selected to assess the soot characteristic residence time in the flame. While the mixture-strength flame height $H_{f}$ emphasizes the processes from fuel pyrolysis to soot growth in the flame, the visible flame height $H_{v}$ includes additionally the soot oxidation in the flame. In the present paper, both heights are considered.

In addition, though the adiabatic temperature was used as the characteristic temperature in Eq.(4) by previous studies [5, 6], radiative losses attributed to soot is believed to affect to a potentially significant extent the assessment of the effects related to nitrogen dilution. As a result, the temperature measured at the location of the maximum local soot volume fraction is considered a relevant alternative for two main reasons. First, the location of the maximum soot volume fraction stands within the flame wings, i.e. away from the flame's axis $[12,14]$. Yet, along the deconvolution process outlined further, the error propagates towards the flame axis though it is decently regularized by a Tikhonov procedure [12]. Furthermore, the raw information that allows for the temperature measurement by the MAE technique is the spectral emission rate field. At the location of the maximum soot volume fraction, the level of spectral emission rate is relatively high. Consequently, the selected temperature is less prone to be affected by the error attributed to the temperature retrieval methodology. 
Second, the location of the maximum local soot volume fraction lies between the soot growth and soot oxidation regions. Thus, the temperature at this location characterizes the conditions at which soot formation stops being the dominant process in the balance between formation and oxidation.

\subsection{Optical diagnostics}

A Phantom V711 camera with a gated intensified mega-pixel CMOS sensor provides 8-bit black and white frames of each visible flame on a $1280 \times 800$ pixels ${ }^{2}$ matrix at 100 frames per second. The exposure time is kept constant at $10 \mathrm{~ms}$. The intensification is also kept constant so that the dynamic range is fully used while the saturation is not reached over the range of investigated conditions. The camera is focused on the plane containing the burner axis of symmetry and the entire flame is captured in the middle of camera sensor. With the above optical settings, these flame sheets show a weak sensitivity to the postprocessing parameters. For every $N_{2}$ dilution condition, the flame displayed on the left in Fig.1 is the average of the 100 instantaneous frames.

The MAE technique is implemented to retrieve the soot temperature and volume fraction fields strictly as outlined in Ref.[12]. Only the major features are reminded briefly. This technique is based on the fact that absorption and emission in the ethylene diffusion flame are mainly attributed to soot in the upper part of the visible spectrum. Two continuous wave lasers operating at $\lambda_{1}=645 \mathrm{~nm}$ and $\lambda_{2}=785 \mathrm{~nm}$ are expanded to provide $60 \mathrm{~mm}$ diameter collimated beams. At every wavelength, the measurement of the laser beam attenuation through the flame is conducted using a CMOS camera. After a deconvolution process incorporating a regularization procedure [14], the local absorption co-

efficient field $\kappa_{\lambda}(r, z)$ can then be mapped and the soot volume fraction field $S V F(r, z)$ be inferred. The Mie theory allows $\kappa_{\lambda}$ to be transformed into $S V F$, 
assuming that soot particles are in the Rayleigh limit [14]:

$$
S V F(r, z)=\frac{\lambda \kappa_{\lambda}(r, z)}{6 \pi E(m)}
$$

where $E(m)$ is a function of the complex refractive index $m$ of soot.

For every spectral range, the flame spontaneous emission is also imaged by the corresponding camera as the laser is off. The local spectral emission rates $\kappa_{\lambda} B_{\lambda}(r, z)$ that are attributed to soot within both spectral ranges are then computed following a similar deconvolution process. $B_{\lambda}$ is here the spectral blackbody radiative intensity at the local temperature given by the Planck's law. Given the retrieved $\kappa_{\lambda}(r, z), B_{\lambda}(r, z)$ can then be extracted when computing the ratio $\kappa_{\lambda} B_{\lambda} / \kappa_{\lambda}$. Thus, the map of soot temperature $T(r, z)$ can be inferred from the field of the ratio $B_{\lambda_{2}} / B_{\lambda_{1}}$ provided a calibration procedure. To this end, the beam delivered by a Halogen calibration light source is imaged on both CMOS sensors. A specific lookup table can then be established providing $T_{\text {ratio }}$ as a function of the ratio $B_{\lambda_{2}} / B_{\lambda_{1}}$ corrected for the characteristics of the CMOS sensors and the optics encompassed between the flame's location and these sensors. In addition, both fields of $B_{\lambda_{1}}(r, z)$ and $B_{\lambda_{2}}(r, z)$ can then be calibrated given $T_{\text {ratio }}$, leading to the temperature fields $T_{\text {red }}$ and $T_{\text {infrared }}$. Following the methodology prescribed by Legros et al. [12], all temperature fields are restricted to locations where the uncertainty does not exceed $\pm 50 \mathrm{~K}$.

\section{Results and discussion}

\subsection{Flame height}

The flame appearance variation with different $N_{2}$ volume fraction in the fuel side is shown on the left in Fig.1. The visible flame height $H_{v}$ is accounted from the burner tip $(\mathrm{HAB}=0)$ up to the flame central tip. To evaluate the 
mixture-strength flame height $H_{f}$, McEnally [10] measured the length from the flame bottom to the location of the peak temperature along the flame centerline (maximum carbon dioxide concentration), which is verified very close to the stoichiometric mixture surface. However, due to our temperature retrieval methodology and its limitations, the temperature profile on the flame axis is prone to fluctuate, which delivers a limited precision for $H_{f}$ assessment. Nevertheless, since the temperature reconstruction is inferred from accurate imaging of the soot emission rate, the maximum soot emission rate position along the centerline is a decent indicator for the maximum temperature point. Therefore, a more accurate increasing $H_{f}$ variation is shown on the right in Fig.1. Interestingly, it has the opposite trend to the overall visible flame height $H_{v}$ variation. $H_{f}$ increases mainly because the soot inception region is shifted downstream, which is easily observed by the series of flame images in Fig.1. This $H_{f}$ evolution is consistent with what McEnally obtained for $N_{2}$ volume fraction ranging from $66.7 \%$ to $85.7 \%$ in a very similar experimental configuration [10]. Although the soot inception is delayed, the soot oxidation region considerably shrinks due to the lower level of soot formed in the flame, and eventually $H_{v}$ is shortened. This reason is also an explanation for $\mathrm{CO}_{2}$ diluted flame height shrinkage $[3,18]$. Indeed, this overall flame height is the result of the competition between the spread of the soot inception region and the shrinkage of the soot oxidation one. Consequently, $H_{f}$ is more relevant to scale the soot formation rate in the soot growth region, while $H_{v}$ is more suitable for the characterization of the overall soot propensity behaviour in the flame. On the other hand, the flame diameter did not change significantly along the $N_{2}$ addition to the fuel side within our dilution range. Thus, the influence of $L_{\max }$ variation is considered negligible in the present study. 


\subsection{Soot volume fraction and temperature fields}

Fig.2 exhibits the soot volume fraction (left) and temperature (right) fields variation for different $N_{2}$ dilution conditions. Due to the limited diameter of the collimated laser beam, the whole flame cannot be probed by the MAE technique. However, the dynamics of the soot temperature and volume fraction fields for the different $N_{2}$ dilution conditions can be captured. With increasing $X_{N_{2}}$, soot volume fraction is gradually reduced in the overall flame, while the maximum soot volume fraction zone remains on the annular region of the flame. Quantitatively, the maximum local soot volume fraction decreases from $11 \mathrm{ppm}$ to $4 \mathrm{ppm}$ as $\mathrm{N}_{2}$ volume fraction rises from 0 to $56 \%$.

In Fig.2, the detectable temperature is confined to the soot existent region in the flame. Nevertheless, a slight temperature decrease can be anticipated, as the calculated adiabatic temperature is reduced by about $128 \mathrm{~K}$ within the range of $N_{2}$ dilution. By careful comparison, the maximum flame temperature moves slightly downstream due to the stretched $H_{f}$. This trend is also reported in previous studies $[10,19]$. Finally, the characteristic temperatures for every $N_{2}$ dilution condition are extracted from experimental fields and shown in Tab.1.

\subsection{Activation energy and thermal effect}

Fig.3 displays the evolution of axial average soot volume fraction $F_{\text {soot }}$ along the flame height for different $N_{2}$ volume fractions, which is calculated by Eq.(3). For every dilution case, $F_{\text {soot }}$ follows the same trend, first increasing then decreasing, the peak slightly moving downstream with increasing $X_{N_{2}}$. To be more specific, the peak $F_{\max }$ reduces approximately from $5 \mathrm{ppm}$ to $2 \mathrm{ppm}$ with increasing $X_{N_{2}}$, which will be applied to the following Arrhenius plots.

According to Eq.(4), the normalized maximum soot volume fractions $\ln \left(F_{\max } L_{\max } / X_{F} H^{0.5}\right)$ versus the inverse of the characteristic temperature $(1 / T)$ are shown in Fig.4. 
For comparison reason, Fig.4(a) shows the derived activation energy based on the adiabatic temperature, while Fig.4(b) exhibits that based on experimentally probed temperature $\left(T_{r e d}\right)$. The temperature uncertainties $( \pm 50 \mathrm{~K})$ lead to the indicated error bars. Additionally, the linear regressions for the different flame heights are incorporated in both plots.

The experimental temperature based plot is right-shifted with respect to that based on the adiabatic temperature due to the cooler experimentally probed temperature. The derived activation energies in plot (a) are $199.2 \mathrm{~kJ} / \mathrm{mol}$ for $H_{v}$ and $223.1 \mathrm{~kJ} / \mathrm{mol}$ for $H_{f}$. These values are similar to those reported by previous studies $[5,6]$. In plot (b), the obtained activation energies are 99.9 $\mathrm{kJ} / \mathrm{mol}$ and $105.2 \mathrm{~kJ} / \mathrm{mol}$ for $H_{v}$ and $H_{f}$, respectively. In general, using the experimentally probed temperature results in about $100 \mathrm{~kJ} / \mathrm{mol}$ reduction in activation energy, which is mainly caused by lower actual temperature in the flame. For this reason, the thermal effect in the flame could be overestimated due to the higher thermal diffusivity, lower kinematic viscosity, etc. when using the adiabatic temperature in the Arrhenius plots. On the other hand, in both (a) and (b) plots, although $H_{f}$ and $H_{v}$ exhibit opposed trends, this only leads to steeper slopes of the fitted Arrhenius plots, i.e. a slight discrepancy in the activation energy. Although the activation energy variation is unremarkable, it does affect the respective extent of the dilution effect and the thermal one on the sooting propensity in the flame. Thus, it is reasonable that the mixture-strength flame height characterizes the soot formation rate in the soot growth region, and the visible flame height describes the overall soot propensity behaviour in the flame. Additionally, the weak activation energy changes mean that the impact of the flame height selection is not as important as the characteristic temperature one.

However, the experimental characteristic temperature can be sensitive to the 
Table 2: Derived activation energy $E_{a}(\mathrm{~kJ} / \mathrm{mol})$ for different flame heights and characteristic temperatures.

\begin{tabular}{c|cccc}
$\mathrm{T}$ & $T_{\text {adi }}$ & $T_{\text {red }}$ & $T_{\text {infrared }}$ & $T_{\text {ratio }}$ \\
\hline$H_{v}$ & 199.2 & 99.9 & 91.8 & 87.8 \\
$H_{f}$ & 223.1 & 105.2 & 96.8 & 88.8
\end{tabular}

different procedures that are allowed by the MAE technique to retrieve the soot temperature field. For this reason, the other two experimental characteristic temperatures that the MAE delivers, i.e. $T_{\text {infrared }}$ and $T_{\text {ratio }}$, were also used to evaluate the activation energy. All the derived activation energies are reported in Tab.2. This allows the range of uncertainty on the experimental activation energy to be assessed at about $\pm 6 \mathrm{~kJ} / \mathrm{mol}$.

\subsection{Discrimination of the dilution and thermal effects}

To further quantify the dilution effect and thermal effect, the soot formation rate $\dot{m}_{\text {soot }}^{\prime}$ is assessed by Eq.(4). In Fig.5(a), the adiabatic temperature, the mixture-strength flame height $H_{f}$ and activation energy of $223.1 \mathrm{~kJ} / \mathrm{mol}$ are selected to calculate the soot formation rate, that the black squares indicate. The blue circles stand for the adiabatic temperature and the blue solid line is the fitted adiabatic temperature $T_{f i t}$. Thus, the black dash line is the modeled soot formation rate $V$ as evaluated by Eq.(6):

$$
V=\frac{X_{C_{2} H_{4}} * \sqrt{H_{f}}}{L_{\max }} * \exp \left(\frac{-2.231 * 10^{5}}{R^{0} T_{f i t}}\right)
$$

The red dash line $\left(V_{T}\right)$ is the relative thermal effect setting $X_{C_{2} H_{4}}=1$ in Eq.(6). The green dash line $\left(V_{D}\right)$ indicates the relative dilution effect setting $T=2363 K$ in Eq.(6), i.e. the adiabatic temperature for $X_{N_{2}}=0$. It is worth noticing that all quantities are normalized with respect to the reference con- 
ditions, i.e. $X_{N_{2}}=0$. Following the calculation methodology described above and incorporating the experimentally probed temperature, the mixture-strength flame height $H_{f}$, and the activation energy $105.2 \mathrm{~kJ} / \mathrm{mol}$ into Eq.(4), a similar plot is drawn in Fig.5(b). The comparison will demonstrate the respective extent of the dilution effect and the thermal one altered by the characteristic temperature selection.

In Fig.5(a), since the adiabatic temperature can be extrapolated beyond the experimental diluted range, the fitted temperature profile tends towards zero when $X_{C_{2} H_{4}}$ does so. However, in Fig.5 (b), the relative analysis are only confined to the experimental diluted range $\left(X_{C_{2} H_{4}}\right.$ ranging from 1 to 0.44$)$, but this plot reflects the actual contributions of both effects in the flame. First of all, both plots clearly illustrate the relative contribution of $V_{T}$ and $V_{D}$ to soot formation rate $V$. Within this experimental range, although the discrepancy between both activation energies is significant, it does not change the fact that the soot formation rate mainly depends on the dilution effect, but hardly on the thermal one. This finding is supported by Gülder et al. [6], who found that for fuel fraction larger than 0.3 , the dilution effect is stronger than the thermal one. Similarly, the fuel fraction boundary around 0.25 is reported by Axelbaum et al. [5]. Inspecting plot (a), when $X_{C_{2} H_{4}}$ is lower than 0.2, the thermal effect tends to dominate the soot formation rate in our study. In addition, by closer comparison, $V_{T}$ is approximately $10 \%$ overestimated in plot (a) compared to that in plot (b) within the experimental dilution range, e.g., at $X_{C_{2} H_{4}}=0.6, V_{T}=$ 0.9 in plot (a), while $V_{T}=0.8$ in plot (b). This again indicates that the thermal effect is overestimated due to the higher adiabatic temperature. Therefore, the actual soot temperature is recommended as a more relevant parameter for the discrimination between both aforementioned effects, especially for the lower dilution conditions. Conversely, $V_{D}$ is closer to $V$ in plot (a) than in plot (b), 
which means that the dilution effect influence turns out to be weaker in actual flame conditions.

\section{Conclusion}

In this work, the variations of flame geometry, soot volume fraction and temperature in axisymmetric laminar diffusion flames are investigated when $N_{2}$ is added to the fuel side of the coflow laminar axisymmetric ethylene diffusion flame. The mixture-strength flame height and the visible flame height are extracted and turn out to have opposite trends with $X_{N_{2}}$ ranging from 0 to 0.56. Globally, when increasing $X_{N_{2}}$, soot is gradually suppressed throughout the flame and soot temperature slightly decreases. Two featured flame heights and the probed soot temperature at the location of the peak soot volume fraction are incorporated to the soot formation rate to investigate the extent of the dilution and thermal effects. Consequently, the probed soot temperature is recommended to evaluate the contribution of the dilution effect and the thermal one, since the activation energy drops by about $100 \mathrm{~kJ} / \mathrm{mol}$. This indicates that using the adiabatic temperature the thermal effect is significantly overestimated. Furthermore, the selection of the characteristic flame height results in quite similar activation energies.

In addition, within the experimental diluted range $\left(X_{C_{2} H_{4}}\right.$ ranging from 1 to 0.44), the soot formation rate depends to a higher extent on the dilution effect than on the thermal one. Following extrapolated models, the thermal effect becomes more important only when $X_{C_{2} H_{4}}$ is lower than about 0.2 .

Eventually, further work needs to be performed to determine to what extent the results can be influenced by the potential chemical effect due to reactive species such as $\mathrm{CO}_{2}$ or $\mathrm{O}_{2}$. 
[1] M.F. Yao, Q.C. Zhang, H.F. Liu, SAE paper no. 2010-01-1125 (2010).

[2] D.X. Du, R.L. Axelbaum, K.C. Law, 23rd symp. (Intl.) combust. 23 (1991) 1501-1507.

[3] F.S. Liu, H.S. Guo, G.J. Smallwood, Combust. Flame 125 (2001) 778-787.

[4] Ö. Gülder, Combust. Flame 101 (1995) 302-310.

[5] R.L. Axelbaum, C.K. Law, 23rd symp. (Intl.) combust. (1990) 1517-1523.

[6] Ö. Gülder, D.R.Smelling, Combust. Flame 92 (1993) 115-124.

[7] I. Glassman, Combustion, 3rd ed., Academic Press (1996) 407-409.

[8] F.G. Roper, Combust. Flame 29 (1977) 219.

[9] D.X. Du, R.L. Axelbaum, K.C. Law, Combust. Flame 102 (1995) 11-20.

[10] C.S. McEnally, L.D. Pfefferle, Combust. Sci. Technol. 151 (2000) 133-155.

[11] F. Liu, H. Guo, G.J. Smallwood, Ö.L. Gülder, Combust. Theory Modelling 7 (2003) 301-315.

[12] G. Legros, Q. Wang, J. Bonnety, Combust. Flame 162 (2015) 2705-2719.

[13] R.J. Santoro, H.G. Semerjian, R.A. Dobbins, Combust. Flame 51 (1983) 202-218.

[14] M. Kashif, J. Bonnety, P. Guibert, C. Morin, G. Legros, Opt. Exp. 20 (2012) 28742-28751.

[15] M. Kashif, J. Bonnety, A. Matynia, P. Da Costa, G. Legros, Combust. Flame 161 (2015) 1840-1847.

[16] G. Legros, T. Gomez, M. Fessard, T. Gouache, T. Ader, P. Guibert, P. Sagaut, J.L. Torero, Proc. Combust. Inst. 33 (2011) 1095-1103.

[17] Ö. Gülder, D.R. Smelling, R.A. Sawchuk, 26th symp. (Intl.) combust. (1996) 2351-2358.

[18] M. Kashif, P. Guibert, J. Bonnety, G. Legros, Combust. Flame 161 (2014) 1575-1586.

[19] A.E. Karatas, Ö. Gülder, Combust. Flame 162 (2015) 1566-1574. 

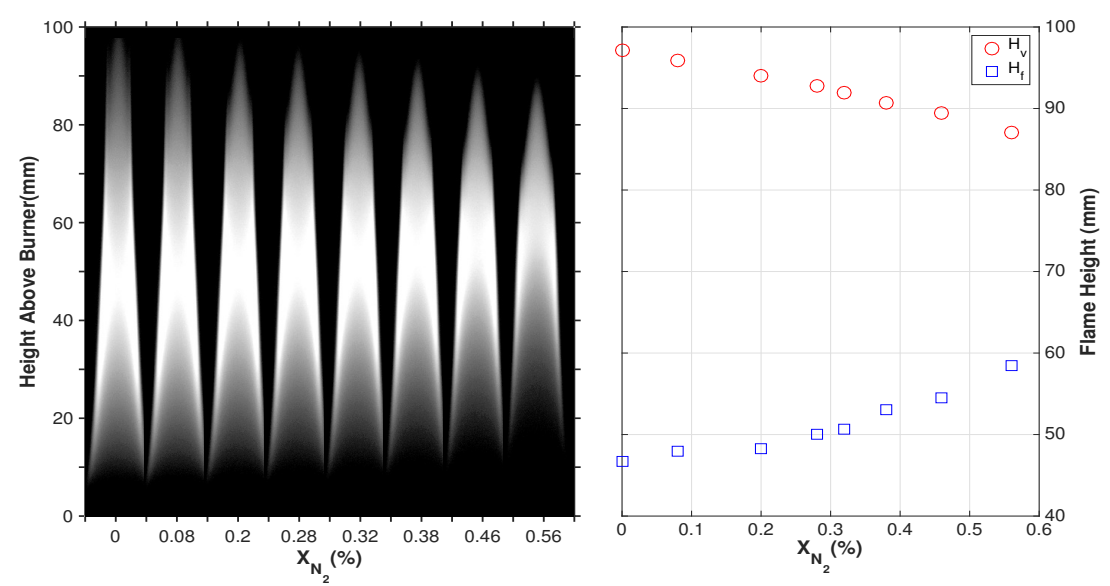

Figure 1: Evolution of the visible flame height $H_{v}$ and mixture-strength flame height $H_{f}$ with increasing $X_{N_{2}}$ in the fuel side. 


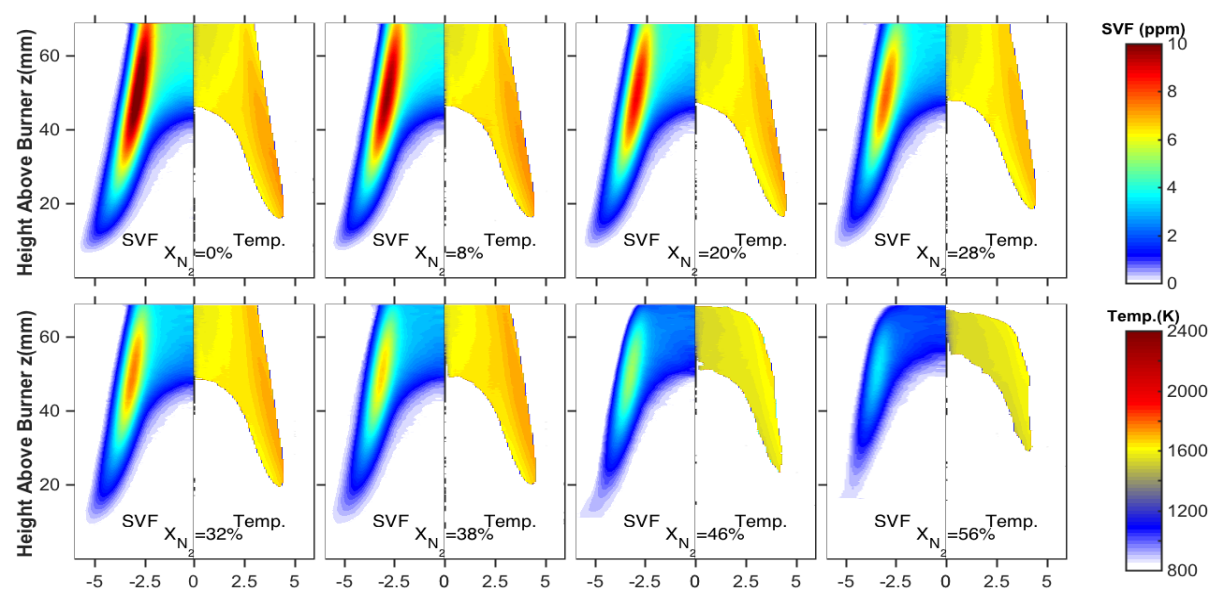

Figure 2: Evolution of two-dimensional soot volume fraction (left side) and temperature (right side) fields with increasing $X_{N_{2}}$ in the fuel side. These fields are inferred from the red absorption and red emission measurements, respectively. 


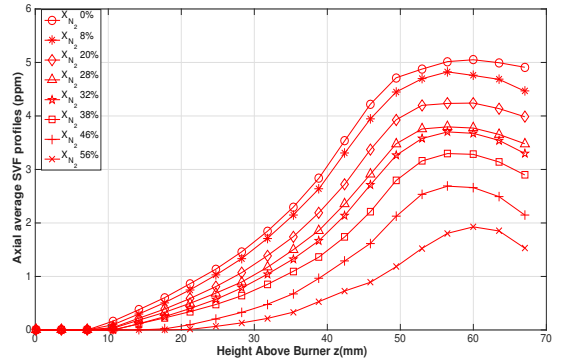

Figure 3: Evolution of the axial average soot volume fraction with increasing $X_{N_{2}}$ in the fuel side. 


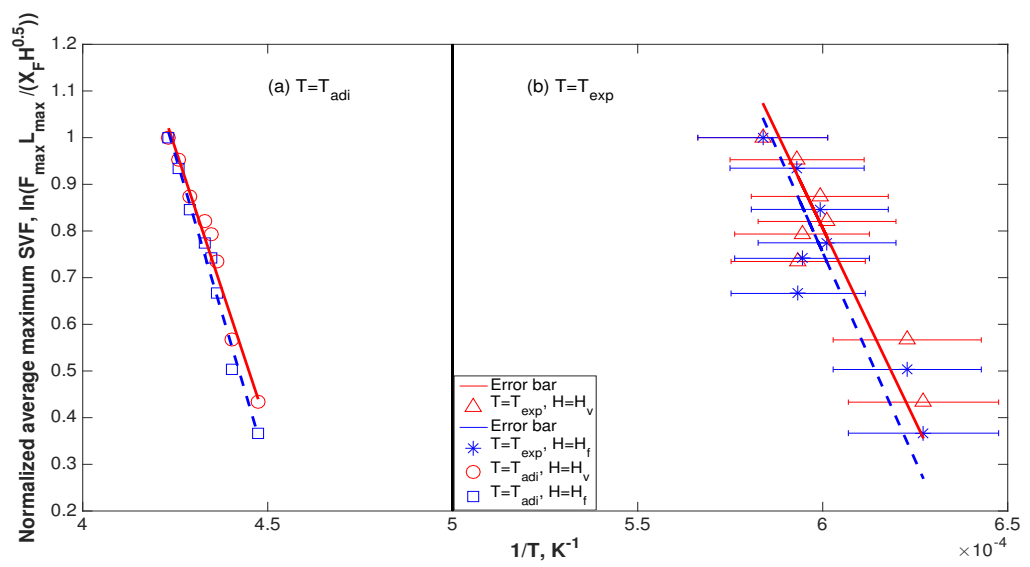

Figure 4: Arrhenius plots of the normalized maximum soot volume fractions versus the inverse of the flame characteristic temperature within the $N_{2}$ dilution cases. (a) The adiabatic temperature is used as the flame characteristic temperature. " $\bigcirc$ " stands for the corrected maximum soot volume fraction for flame height $H_{v}$; " $\square$ " represents the corrected maximum soot volume fraction for flame height $H_{f}$. (b) The experimentally probed temperature is used as the flame characteristic temperature. " $\triangle$ " indicates the corrected maximum soot volume fraction for flame height $H_{v}$. "*" stands for the corrected maximum soot volume fraction for flame height $H_{f}$. The markers are the experimental data and the lines are the fits. 


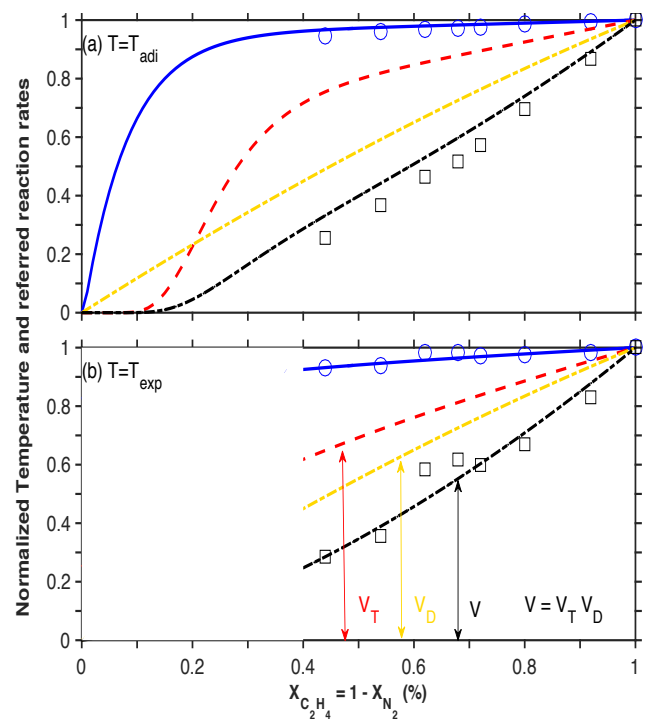

Figure 5: Relative contributions of the dilution effect and the thermal one on the soot formation rate. (a) The adiabatic temperature is used to evaluate the dilution and thermal effects. The blue " $\bigcirc$ " stands for the calculated adiabatic temperature. The blue solid line $\left(T_{f i t}\right)$ is the fitted adiabatic temperature profile. (b) The experimentally probed temperature $T_{\text {exp }}$ is used to assess both effects within the experimental fuel fraction $X_{C_{2} H_{4}}$ ranges. The blue " $\bigcirc$ " stands for the experimentally probed temperature. The blue solid line $\left(T_{f i t}\right)$ is the modeled experimentally probed temperature. In both plots, " $\square$ " represents the calculated soot formation rate; Black dash line is the fitted soot formation rate. The red dash line $\left(V_{T}\right)$ is the relative thermal effect. The green dash line $\left(V_{D}\right)$ indicates the relative dilution effect. All temperatures and inferred rates are normalized with respect to the reference condition $\left(X_{C_{2} H_{4}}=1\right)$. 


\section{List of Figures}

1 Evolution of the visible flame height $H_{v}$ and mixture-strength flame height $H_{f}$ with increasing $X_{N_{2}}$ in the fuel side. . . . . . . . . . . . .

2 Evolution of two-dimensional soot volume fraction (left side) and temperature (right side) fields with increasing $X_{N_{2}}$ in the fuel side. These fields are inferred from the red absorption and red emission measurements, respectively. . . . . . . . . . . . . . . .

3 Evolution of the axial average soot volume fraction with increasing $X_{N_{2}}$ in the fuel side. . . . . . . . . . . . . . . . . . .

4 Arrhenius plots of the normalized maximum soot volume fractions versus the inverse of the flame characteristic temperature within the $N_{2}$ dilution cases. (a) The adiabatic temperature is used as the flame characteristic temperature. " $\bigcirc$ " stands for the corrected maximum soot volume fraction for flame height $H_{v}$; " $\square$ " represents the corrected maximum soot volume fraction for flame height $H_{f}$. (b) The experimentally probed temperature is used as the flame characteristic temperature. " $\triangle$ " indicates the corrected maximum soot volume fraction for flame height $H_{v}$. "*" stands for the corrected maximum soot volume fraction for flame height $H_{f}$. The markers are the experimental data and the lines are the fits. . . . . . . . . . . . . . . .

5 Relative contributions of the dilution effect and the thermal one on the soot formation rate. (a) The adiabatic temperature is used to evaluate the dilution and thermal effects. The blue " $\bigcirc$ " stands for the calculated adiabatic temperature. The blue solid line $\left(T_{f i t}\right)$ is the fitted adiabatic temperature profile. (b) The experimentally probed temperature $T_{\text {exp }}$ is used to assess both effects within the experimental fuel fraction $X_{C_{2} H_{4}}$ ranges. The blue " $\bigcirc$ " stands for the experimentally probed temperature. The blue solid line $\left(T_{f i t}\right)$ is the modeled experimentally probed temperature. In both plots, " $\square$ " represents the calculated soot formation rate; Black dash line is the fitted soot formation rate. The red dash line $\left(V_{T}\right)$ is the relative thermal effect. The green dash line $\left(V_{D}\right)$ indicates the relative dilution effect. All temperatures and inferred rates are normalized with respect to the reference condition $\left(X_{C_{2} H_{4}}=1\right)$. 


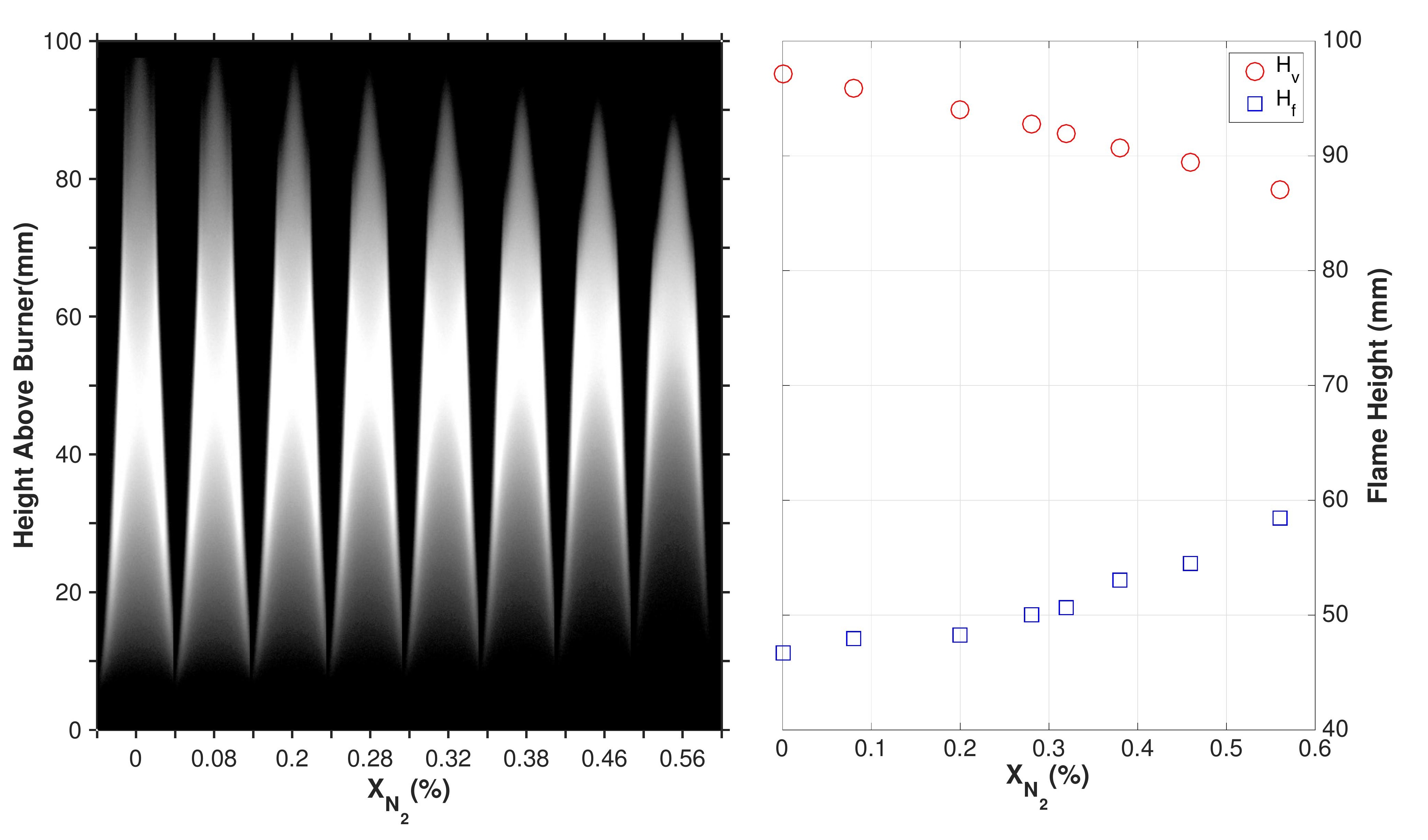




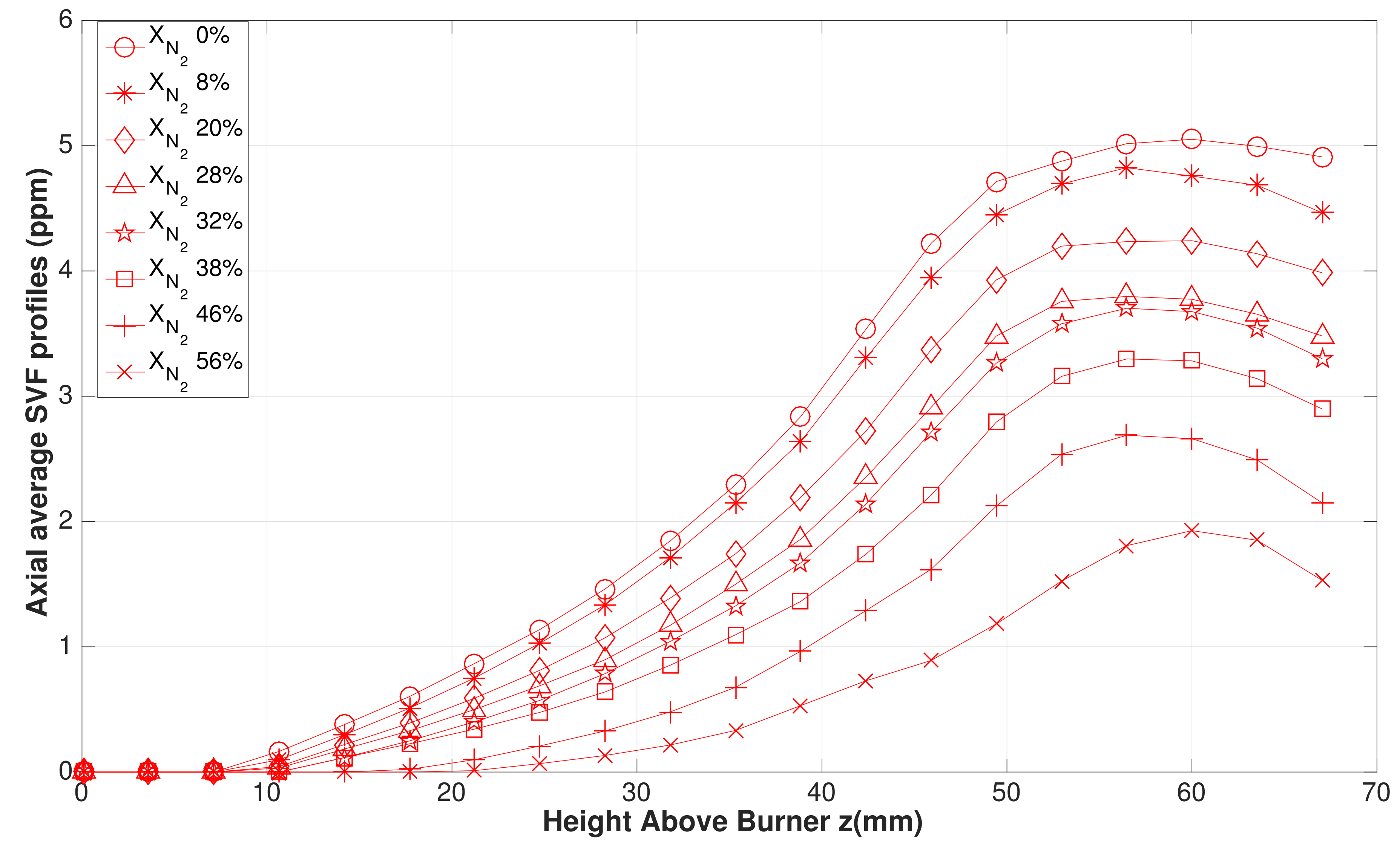




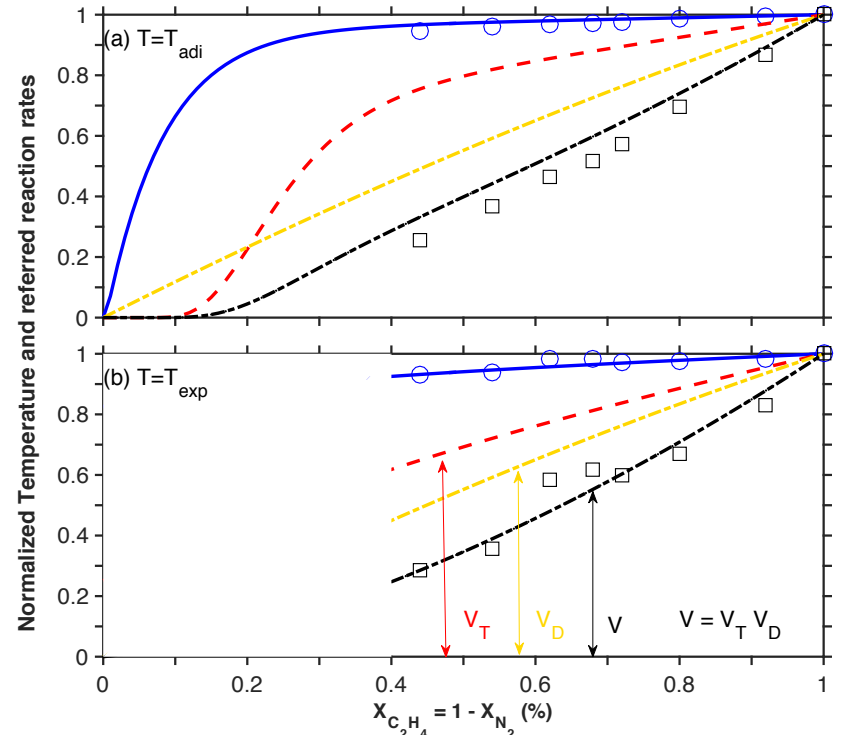

